\title{
AWARENESS AND GEOSPATIAL EXAMINATION OF HEALTHCARE FACILITIES IN OGUN STATE NIGERIA: NEED FOR HEALTH CARE DEVELOPMENT
}

\author{
Dominic Ezinwa Azuh ${ }^{1 *}$, Gideon Adewale Adeyemi ${ }^{2}$, Paul Akinniyi Akinduti ${ }^{3}$, Grace \\ lyabo Olasehinde ${ }^{4}$, Olusegun Peter Olaoye ${ }^{5}$ and Timothy Ayomitunde Aderemi ${ }^{6}$ \\ ${ }^{1}$ Dr. Covenant University, The Nigeria, dominic.azuh@covenantuniversity.edu.ng \\ ${ }^{2}$ Mr., Covenant University, The Nigeria, gideon.adewale@covenantuniversity.edu.ng \\ ${ }^{3}$ Dr., Covenant University, The Nigeria, paul.akinduti@covenantuniversity.edu.ng \\ ${ }^{4}$ Prof., Covenant University, The Nigeria, grace.olasehinde@covenantuniversity.edu.ng \\ ${ }^{5} \mathrm{Mr}$., Covenant University, The Nigeria, segun.olaoye@covenantuniversity.edu.ng \\ ${ }^{6}$ Dr., Bells University of Technology, The Nigeria, aderemi.timothy@covenantuniversity.edu.ng \\ ${ }^{*}$ Corresponding Author
}

\begin{abstract}
Spatial distribution inequity in health care facilities, including primary health care, has been recognized as a wedge towards effective delivery of such services in many countries, including Nigeria. Healthcare facilities are vehicles to attain an acceptable level of health that will enable everyone to lead a socially and economically productive life. One of the core challenges facing the Nigerian health care system is poor access to health facilities, worsened by poverty, poor road networks and transportation. The resultant consequences are high morbidity and mortality in most parts of the country, leading to low economic performance. Access serves as the bridge between availability and utilization. For Sustainable Development Goal 3, people should have access to health facilities closer to their residence. The study employed secondary data and geographic information system mapping in the investigation. The paper aimed to explore the locational distribution of existing health facilities in Ogun State and make informed recommendations for policy intervention in the study area. The study reveals that the distribution pattern of public healthcare facilities in the State is not uniform either at tertiary, secondary, or primary levels. And this scenario negates the essence of providing health care facilities within 5 kilometers distance envisaged by WHO and general health status. Densely populated health facilities were seen in local governments with high populations, industries and Local Government capitals. In contrast, others have fewer health care facilities, perhaps due to their rural and remote nature. Thus, the government needs to ensure even distribution of health facilities and motivated personnel, drugs, and deliverables in the study area to ensure optimal spatial efficiency.
\end{abstract}

Keywords: Geospatial, health facilities, distributions, mortality, SDG3

\section{INTRODUCTION}

In Nigeria, the public health care system continuously depreciated and in deplorable conditions worsened by the dwindling funding from the government and ongoing strike of medical personnel. This has made the primary goal of healthcare delivery for all citizens to remain vague and unachievable. Public health facilities are health facilities owned and fully funded by government (Uwala, 2020). While lack of access to health 
services is a significant problem in the US mostly for poor or near poor people, access to health care is the poorest in Africa (Paez et al, 2010; WHO, 2010; WHO, 2019). In Nigeria, public health facilities accounted for 73 percent of all health care facilities and observed that only 40 percent of Nigerians patronize public hospitals at federal, state and local government levels (Ofoli, 2019). And this might not be unconnected with the haphazard location of the available health facilities where a significant percentage of the populace have no access to them (Owoyele et al, 2015; Olugbamila, 2018). Substantial progress would have been made in health sector in Nigeria in the past years, but geospatial distribution and location have made health care to be costly, inaccessible and unaffordable with a resultant increase in morbidity and mortality in several parts of the State. Considering the need for healthcare development in Ogun State, the geospatial analysis would be focusing on developmental needs in the overall health care system. Nigeria's landscape is not uniform; it is characterized by heterogeneous forms leading to diversity in ecological variations. This heterogeneity creates a significant challenge concerning location of basic infrastructural facilities including health service, particularly in rural areas where more significant proportion of the population live. In Ogun State, health facilities are not uniformly distributed and are not in favor of rural areas. The situation is aggravated with poor road networks and poor transport leading to accessibility challenges among rural dwellers in utilization of primary health care services in Ogun state. Nigeria's population, currently the seventh largest in the world, proliferating, is projected to surpass that of the United States by year 2050 and would become the fourth largest country globally with a population of 402 million (Population Reference Bureau, 2017).

Ogun State is one of the 36 States of the Federal Republic of Nigeria and was carved out of the defunct Western State on the $3^{\text {rd }}$ of February, 1976. It covers a total land area of $16,40.26$ square kilometers and a population of 3,751,140 (National Population Commission, 2009). The capital of the State is Abeokuta and has 20 local government areas (LGAs), each with several political wards. Generally, health care services are not yet up to the expected level in the State. Nigeria's health care system is weak, and affects not only the vulnerable population but also renders the active population unproductive leading to low developmental activities which retards the realization of Sustainable Development Goals (SDG 3). The country was placed in the 140th position, with 51 points out the assessed 195 nations on healthcare quality and access on the report's Healthcare Access and Quality Index (Atuma, 2017). Primary health care formed the nucleus of broad range of health care services to serve the family's daily needs and was designed as a result of the Alma-Ata International Conference in 1978 to stimulate the efforts of the government in the welfare of the people especially their health needs (World Health Organization, 1978).

Optimal locations of health facilities are essential in creating access to health care services, improved health outcomes and better quality of life. However, the extension of adequate health services to cover the entire countryside is a function of the distribution or location of these health facility service points. Invariably, it is crucial to note that the extent to which health needs are met now and in future depends on their closeness to residential areas. Distance of health care facility determines the health-seeking behavior of individuals and households towards self-treatment, consultations with traditional or orthodox medical practitioners. In many studies, geographical proximity is the leading factor influencing the choice of healthcare facility Gabrysch et al, 2011).

Seeking health care for either individual or household is a complex decision, which involves a web of consideration of several factors such as location of health facility, accessibility, affordability, and infrastructure, service delivery and client's satisfaction, particularly among rural communities. Sunday and Ogundmu (2015) found a significant relationship between health care location and utilization. Those who live far away from maternity services could not attend their antenatal care clinic regularly. Inequalities and inequitable distribution of health establishments relative to the population size have been noticed in Nigeria by many researchers (Nwakeze et al, 2011; Oyedepo et al, 2018; Fadahunsi et al, 2017).

Needless to reiterate that the trend has not changed as noticed notwithstanding the Ogun State Rural Medical Scheme (OGRUMED) and other intervention measures, health indicators for the State are still far from acceptance. Health for all citizenry vis-a-vis the SDG 3 may be difficult to achieve as long as access to health facilities remains limited and unevenly distributed with its attendant consequences to the nation's individual and developmental activities. The challenges posed by uneven distribution of health facilities among the various political wards and communities in Ogun State made the study imperative to find out how health facilities affect not only the population but also its accessibility. Hence, the study aimed to examine the locational distribution of existing health facilities in Ogun State and make informed recommendations for policy intervention in the study area

\section{METHODS}

This study is exploratory, secondary data techniques were adopted in the conduct of the study. It utilized the 
literature on health and infrastructure, shape files of hospital locations data in Ogun State were obtained to produce the map of hospital facilities location. The literature on health facilities management systems helps us identify problems confronting health management in the study area, including the implementation of health programs and activities. Health facility establishment by geographical spread in Ogun State is highly uneven. The State has 424 primary health centers, 29 secondary and 2 tertiary health facilities, all across local government areas. Concerning the State health status indicators as of 2009, Doctor/Patient ratio was 1: 5060; Nurse/Patient ratio was 1:201 in PHC respectively, Population per Doctor was 3056:1, Population per Nurse was 1133:1; Population per Health Centre was 5025:1; Population per Hospital was 7725:1 and Population per Hospital Bed was 279:1 as at 2009 (OSMOH, 2009). The above indices remained more or less the same even years after.

\subsection{Results and Discussion}

The distribution of health facilities was observed to be unevenly distributed in the study area. Higher concentrations were observed in some areas and non in other areas. It was observed that the local governments with high populations, industries and the headquarters of the local government were observed to have densely populated health facilities. Abeokuta south is smaller in geographical landmass with high population density, serving as the state capital as shown in Figure 1. The high population in Abeokuta may not be unconnected with more economic activities attracting more people to the area. Ado Odo/ Ota has more industries and also a high population. In the Northern part, Imeko Afon Local government area has fewer health care centers because it is located at the remote part of the State and has more rural communities.

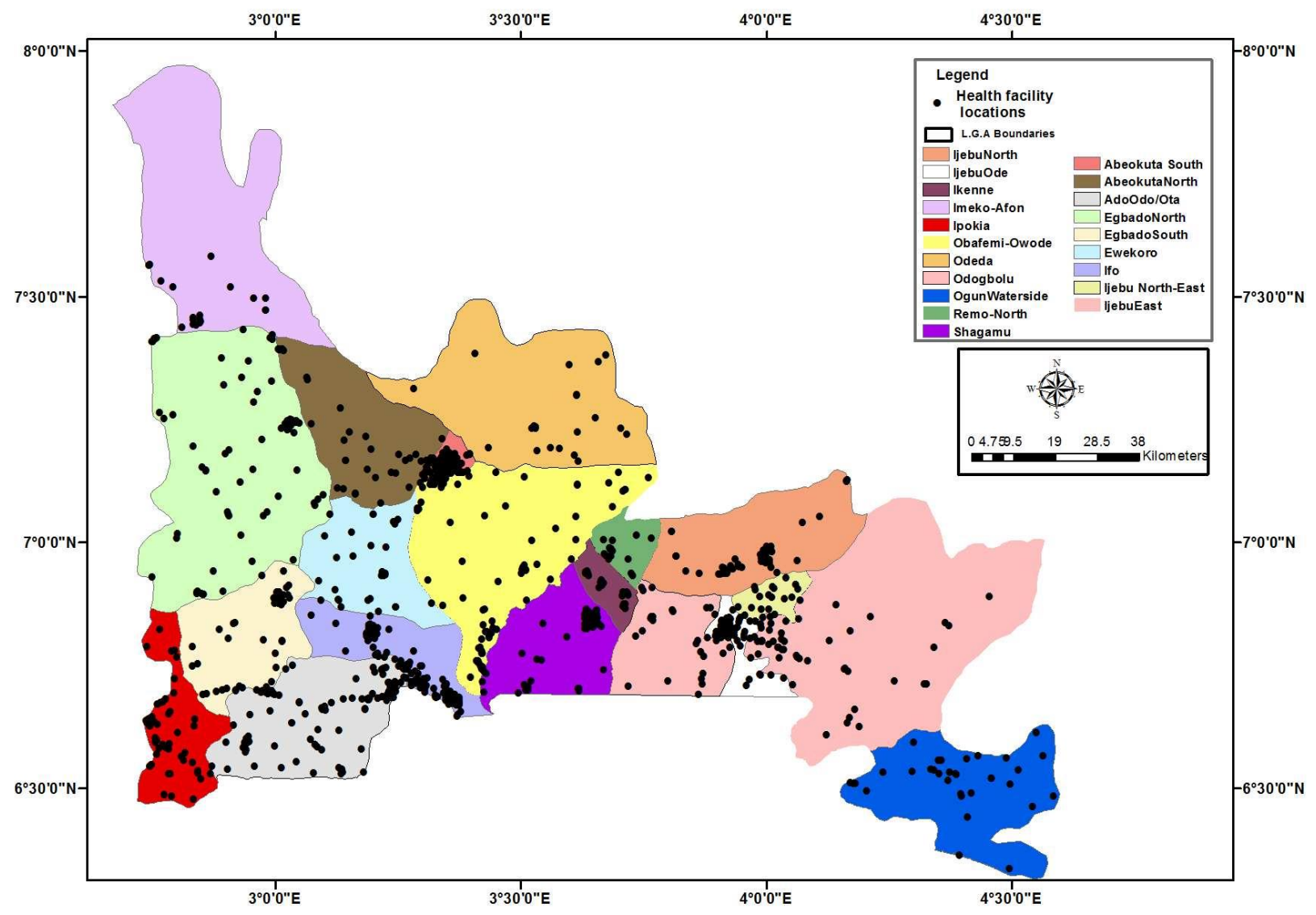

Figure 1; Geospatial distribution of health facilities in various local government in Ogun State, Nigeria

Optimal distribution of health care facilities is crucial for sound health of the population. In other words, good spatial accessibility creates way for high patronage of communities to health care facilities. Awoyemi et al (2011) found unequal access to health facilities in examining factors influencing access to and the use of health facilities in Kogi State, Nigeria. They revealed that long distances to health facilities caused by poor location patterns of health care facilities to be a major barrier to their use. Similarly, Agaja (2012) found that distribution of health care centers clustered in some areas leaving others underserved. Other studies have 
also observed that poor maternal health care to be due to or aggravated by poor access to health care facilities (Abbas et al, 2012; Andersen and Landex 2000; Lowe and Chen. 2016; Azuh et al, 2017). Geographic location has to bear with distance to health facility, traveling time and cost, nature of the road to health facility, all of which determine the choice and use of health facilities especially in rural settings. Bour's also reported the impact of distance on the use of health care services particularly among the rural communities (Bour, 2002) while over $60 \%$ of the health facilities users in Ayedaade local government area of Osun State Nigeria, patronized health facilities within $1 \mathrm{~km}$ distance of their residence and $24 \%$ attend health facilities located at a distance of $4 \mathrm{~km}$ and above (Adetunji, 2003). Musa and Abdulhamed, 2012). also observed that accessibility problems affect the level of utilization of the health facilities in Jigawa State Nigeria; and that the health facilities were unevenly distributed due to political policy and desire to locate the health infrastructural facilities in the urban areas. Likewise, Kibon and Ahmed (2012) observed in their study of health facilities in Kano Metropolis Nigeria, that the distribution of PHC facilities is uneven as most of the facilities were clustered, leaving out some areas.

\subsection{Spatial Distribution, Inadequate Health Facilities and Challenges}

Establishment of hospitals in Ogun State is usually being driven by the population density and funding for health care delivery. The spatial distribution of many health care centers in various locations in Ogun State suggest inadequate and poorly funded hospitals particularly in rural communities (Atser and Akpan, 2009). As a result of this inadequacy, many residents resolved to patronize traditional medical centers which are more prominent in various communities, operating with little or no regulation (Aluko-Arowolo, 2006). Establishment of more healthcare facilities should be one of the priorities of the government to her citizen but political struggle for control had made government at different levels to abandon this project. Despite the fact that hospital setting requires continuous funding, little funds were allocated to rehabilitation and establishment of hospitals, making the spatial distribution of established ones to be compromised. Spatial distribution of many hospitals in Ogun State reveal inadequacy of healthcare delivery as one PHC could be serving a population of more than 300,000 people having poor facilities, ill-equipped and inadequate medical personnel to attend to the overwhelming and increasing population. Due to these inadequate number hospitals, high maternal and neonatal deaths have been on the rise particularly in rural communities (Ajala et al 2005). According to World Health Organization (WHO), health is a state of complete physical, mental, emotional and social well-being (World Health Organization, 1978). Therefore, a good State of health should be the right for every citizen of Ogun state. As good health is desirable in many rural communities, poor funding and mismanagement of facilities have limited access to, affordability and acquisition of good health care in Ogun state. Provision of service-oriented medical care is no longer achievable while diagnostics, research, rehabilitation and therapeutic services are absent or poorly provided due to the allocation of meager funds to health care in rural settings (World Health Organization, 2008). Several types of equipment and diagnostic tools are no longer maintained or managed but practically abandoned or allowed to deteriorate over the years in many rural areas. Spatial distribution of modern and suitable facilities needed in rural areas would be allocated appropriately and monitored for effective service delivery. Advance medical diagnostic equipment could only be accessed in major tertiary hospitals but is even limited in use compared to rural where accessibility to these facilities is very poor and in most cases not available. National health policy was formulated on the principle of social justice and equity with freedom and opportunity to health care, which is a fundamental principle for establishing primary health care (Ujoh and Kwaghsende, 2014; Kibon and Ahmed, 2012).

In rural areas: Reports of spatial evaluation of primary health care particularly in Ogun state showed the level of poor funding and deplorable State of numerous health facilities in Ogun state.

Report on geospatial accessibility index of many rural dwellers in Ogun state to quality and effective drugs is very scanty. Many rural communities in Ogun state lack qualified pharmacists or medical officers that could prescribe quality drugs for any ailment bedeviling the rural dwellers and this has made circulation of fake drugs thrive in many remote parts of rural communities in Ogun State. Several unqualified individuals have turned to 'consultant' prescribing and administering fake and poor brand of different drugs to people in most rural health care centers but the use of spatial analysis would largely aid monitoring and distribution of drugs in most of these rural communities (Akokuwebe and Okafor, 2015). Despite the efforts of National Agency for Drug Administration and Control (NAFDAC), high influx, purchasing and distribution of fake drugs have been observed in many parts and most primary health centers. Many of these drugs were poorly preserved inappropriate storage facilities making them lose their potency and their side effects more severe and remain a source of concern to health system (Boansi et al, 2010). Geospatial analysis of drug distribution will immensely aid monitoring, handling, distribution, expiration check and proper prescription of relevant drugs in rural health centers (Awodele et al, 2018). 


\subsection{Implications of Poor Health Infrastructure}

Several mortalities would have been prevented assuming there are good road infrastructures in many cases of medical emergencies. Poor roads in most rural communities in Ogun state are not inaccessible but dangerous for the residents. This has made medical service remain at a low ebb, giving rise to high mortality (Musa and Abdulhamed, 2012). Attending to surgical and medical emergencies from rural areas is usually delayed and unattended, particularly in pregnancy and accident cases. The implication of poor road infrastructure in many parts of Ogun state communities to health care centers suggests more high deaths from casualties and morbidity from infectious diseases. Geospatial evaluation of road networks in many Ogun communities needed to be evaluated for poor distribution and inaccessibility for health care facilities. The majority of these roads are not motorable due to erosion and poor road management.

Social amenities remain the basic need of the populace for better life and major task of any committed government, towards the welfare and development of her citizens. Despite all efforts to increase delivery of good health care, poor or inadequate social amenities in many rural communities in Ogun state pose a threat to human living and survival. Deplorable social amenities such as good water supply, electricity, mobile network, etc drive much medical personnel away from rural to urban cities. Availability of electricity to power diagnostic equipment or machines has made health delivery almost impracticable and left many on sick beds for a long time before death. The level of basic personal and environmental hygiene in many rural areas aids the spread and dissemination of several communicable diseases that have killed several people particularly children, the elderly and immune compromised individuals (Gelberg et al, 2000). Analysis of these social amenities in several Ogun communities with spatial tools would further reveal the localization and provision of these essential and basic amenities in many communities to alleviate the problem of inaccessibility to quality medical care.

Empirical analysis of medical personnel availability in several rural areas of Ogun State indicates a low number of medical officers, qualified nurses, pharmacists, medical laboratory scientists and others due to poor pay and allowances. Considering the enormous task of providing medical care and its cost, many of the health personnel were not well paid and this has made several of them seek greener pastures in developed counties (Manortey and Acheampong, 2016). Due to this effect, unqualified individuals have exploited rural citizens by providing unregulated medical care, which could maim or prone patients to risk of death. Not only have poor salary payment adversely affected personnel at rural hospitals, constant strikes and labor union agitations have eroded the provision of timely, adequate and quality health care in many parts of Ogun state where primary health care delivery is highly needed. During strikes of medical unions, several lives were usually lost, mostly in rural hospital settings. Evaluation of the impact of strikes and poor salary on medical personnel in rural areas could have been well monitored and effectively managed through spatial performance analysis of medical practice.

\subsection{Conclusion and Recommendations}

Rural dwellers have low access to health care delivery services. In addition, the facilities in rural areas are far less than in urban areas despite the huge proportion of rural population. The low access to health facilities is due to the vast population and the distribution pattern of health facilities within rural communities. The research recommends that the government ensure the establishment of more health care facilities equipped with appropriate medical personnel, equipment, and deliverables in rural areas to guarantee good health for the rural masses and achieve the Sustainable Development Goal 3.

\section{ACKNOWLEDGMENT}

The authors acknowledged Covenant University Center for Research, Innovation, and Discovery (CUCRID) for supporting the publication of this research paper.

\section{REFERENCE LIST}

Abbas et al (2012). Health care facilities Mapping and Database Creation Using GIS in Chikun Local Government, Kaduna State, Nigeria. Global journal of Human Social Science Geography and Environmental Geoscience, vol.12, issue 10: pp. 11-18.

Ademiluyi, I. A. and Aluko-Arowolo, S. O. (2009). Infrastructural Distribution of Health care Services in Nigeria: An Overview. International Journal of Geography and Regional Planning, 2 (5), pp. 104-110. 
Adetunji, M. A. (2003). Geographical Analysis of Rural Transport and Accessibility in Ayedaade Local Government Area of Osun State. An Unpolished M, Sc, Thesis. Department of Geography, Obafemi Awolowo University, lle-Ife, Nigeria.

Agaja, S. A. (2012). Spatial Distribution of Primary Health Care Centers in Ugheli South and Warri south Local Government Areas of Delta State Nigeria. International Journal of Scientific and Technological Research, vol. 1, Issue 9, pp. 38-41.

Ajala, O.A., Sanni, L. and Adeyinka, S.A. (2005), Accessibility to Health Care Facilities: A Panaceafor Sustainable Rural Development in Osun State, Southwestern Nigeria.Journal of Human Ecology, 18(2)

Akokuwebe ME, Okafor EE. Maternal health and the implications for sustainable transformation in Nigeria. Res Humanit Soc Sci. 2015;5(6):1-13.

Aluko, S. O (2008). Health Seeking Behaviour of Pregnant Women among ljebu-Yoruba. An Unpublished M.Phil Disertation in Department of Sociology, University of Ibadan, Ibadan Nigeria.

Aluko-Arowolo .O (2006) The medical spiritual and historical origin of Malarial disease in Falola $T$ and Heaton M.M (Eds.) the traditional and modern health system in Nigeria, Africa world press. Trenton and Asmara: pp.247-256

Andersen, J. L. E. and Landex, a. (2000). GIS-Based Approach to Catchment Area Analysis of Mass Transit. University of Denmark (Internet).

Atser J. and Akpan, P.A. (2009) "Spatial Distribution and Accessibility of Health Facilities in Akwa Ibom State, Nigeria." Ethiopian Journal of Environmental Studies and Management (EJESM) Vol.2 (2), pp. 49-57 www.ajol.info/index.php/ejesm/index

Atuma U, "Nigeria's poor healthcare access ranking," Sun Newspaper, 2017.

Awodele O, Aliu R, Ali I, Oni Y, Adeyeye CM. Patterns of adverse drug reaction signals in NAFDAC pharmacovigilance activities from January to June 2015: safety of drug use in Nigeria. Pharmacol Res Perspect. 2018; 6(5): e00427. doi:10.1002/prp2.427

Awoyemi, T. T. et al (2011). Effect of Distance on Utilization of health care Services in Rural Kogi State, Nigeria. J. Hum Ecol. 35(1), pp. 1-9.

Azuh DE, Azuh AE, Iweala EJ, Adeloye D, Akanbi M, Mordi RC. Factors influencing maternal mortality among rural communities in southwestern Nigeria. Int J Womens Health. 2017; 9:179-188.

Boansi, P.K., Ekekpe, E., and Bonney, A.A (2010), Combating Maternal Mortality in the Gushiegu District of Ghana: The Role of Rural Transportation. Journal of Sustainable

Bour, D. (2002). Distance as a Predominant Factor in the Utilization of Health Services in Kumasi Metropolis Ghana. Geojournal, 56(2):145-157.

Delamater, P. L., Messina, J. P., Shortridge, A. M., \&Grady, S. C. (2012). Measuring geographic accessto health care: Raster and network-based methods. International Journal of Health Geographics, 11-15.

Ejiagha, I.R., Ojiako, J.C. and Eze, C.G. (2012). Analysis of Health Care delivery system within Enugu urban area using Geographic Information System. Journal of Geographic Information System.Pp.279-281

Fadahunsi, J. J., Kufoniyi, O. and Babatimehin, O. I. (2017). Spatial Analysis of Distribution Patterns of Health care Facilities in Ogun State, Nigeria. Universal Journal of Public Health, 5 (7): 331-344.

Fanan Ujoh, Felix Kwaghsende Analysis of the Spatial Distribution of Health Facilities in Benue State, Nigeria Public Health Research 2014, 4(5): 210-218 DOI: 10.5923/j.phr.20140405.09

Federal Government of Nigeria (2004). National Policy on Population for Sustainable Development. Abuja: Federal Government of Nigeria

Federal Ministry of Economic Development [FMOED] (1975). The Third National Development Plan 1975-80, vol. 1, pp. 269-272. Central Planning Office. Lagos: FMOED.

Gabrysch S, S. Cousens,J. Cox, O.M.R. Campbell, "The Influence of Distance and Level of Care on Delivery Place in Rural Zambia: A Study of Linked National Data in a Geographic Information System," PLoS Med, Vol.8, Issue. 1, pp. 1-12, 2011. 
Gelberg, L., R. M. Andersen, and B. D. Leake. 2000. "The Behavioral Model for Vulnerable Populations: Application to Medical Care Use and Outcomes for Homeless People." Health Services Research 34: 1273-302.

Higgs, G. (2004). A Literature Review of the use of GIS-Based Measures of Access to Health Care Services. Health Services and Outcomes Research Methodology, vol. 5, pp. 119-139.

Kibon, U. A. and Ahmed, M. (2012). Distribution of Primary Health Care Facilities in Metropolitan Kano State, Nigeria Using GIS. Research Journal of Environmental and Earth Science, vol. 5(4): 167-176.

Manortey, S. and Acheampong, G.K. (2016) A Spatial Perspective to the Distribution of Healthcare Facilities and Health Personnel in the Eastern Region of Ghana. Open Access Library Journal, 3: e2956. http://dx.doi.org/10.4236/oalib.1102956

Mat Lowe, Duan-Rung Chen Factors influencing the migration of West African health professionals. The Pan African Medical Journal. 2016; 24:237. doi:10.11604/pamj.2016.24.237.9402

Musa, I J and Abdulhamed, I. (2012). The Accessibility problems of primary Health Care to Rural People in Jigawa State, Nigeria. Global Advance Research Journal of Social science, vol. 4, pp. 3-22.

National Population Commission [NPC] (2009). 2006 Population and Housing Census of the Federal Republic of Nigeria. Priority Tables, vol. 1. Abuja: NPC.

Nwakeze, N. M. and Ngianga-Bakwin Kandala (2011). The Spatial Distribution of Health Establishments in Nigeria. African Population Studies, Vol. 25, 2, pp. 680-696.

Ofoli J, "Rationalising Public Hospital Governance and the Quality of Care," A paper presented at the International Conference on Hospital Management and Administration (ICOHMA) Abuja, 2019.

Olugbamila O.B., "Spatial Distribution and Accessibility to Healthcare Facilities in Akure South Local Government Area of Ondo State,"AnaleleUniversitatii din Oradea, Seria Geografie, Vol. 28, Issue.1, pp. 7-18, 2018.

Owoyele G.S., T. O. Ajobiewe, O.O. Idowu, S.I. Shuaibu, V.I. Martin, "Spatial Analysis of health facilities in Suleja, Niger State, Nigeria," Ethiopian Journal of Environmental Studies \& Management, Vol.8, Issue. 3 , pp.264 - 271,2015

Oyedepo, J. A., Elizabeth, O. O. and Emmanuel Olabisi Orebiyi (2018). Spatial Decision Support for Health System Development in Ogun State Nigeria. FUW Trends in Science and Technology Journal, Volume 3, no. 2 A, pp. $425-429$

Population Reference Bureau (2017). World Population Data Sheet. Washington DC: Population Reference Bureau.

Paez A, R.G .Mercado, S. Farber, C. Morency, M. Roorda, "Accessibility to health care facilities in Montreal Island: An application of relative accessibility indicators from the perspective of senior and non-senior residents," International Journal of Health Geographics, Vol. 9, Issue. 5 pp. 2-11, 2010.

Sunday, O. Aluko-Arowolo and Ogundimu Ayobami, O. (2015). Procedia Social and Behavioural Sciences, 185, 307-313.

World Health Organization (1978) Primary Health Care: Report of the International Conference on Primary Health Care. WHO, Alma Ata, Geneva.

World Health Organization, (2008). Primary Health Care Now More Th an Ever, World Health Report, Geneva.

World Health Organization, "World Health Report: Health Systems Financing-The Path to Universal Coverage," Geneva, 2010.

World Health Organization, "World Health Observatory Data. World Health Statistics 2019. Monitoring Health for the SDGs," 2019. 